\title{
RANCANG BANGUN JIG \& FIXTURE UNTUK PIPE FITTING STEEL CONCENTRIC REDUCER PADA MESIN BEVEL PIPA
}

\author{
Nurul Ulfah $^{1}$, Rahman Hakim ${ }^{2}{ }^{\otimes}$, Michael Tri Adelitho ${ }^{3}$ \\ ${ }_{1,2,3}$ Program Studi D3 Teknik Mesin, Jurusan Teknik Mesin, Politeknik Negeri Batam, \\ Jl. A. Yani, Batam Center, Kota Batam. 29461. \\ ๑e-mail:hakim@polibatam.ac.id
}

\begin{abstract}
The development of manufacture Industries in the world rapidly increases especially in Indonesia. One of the manufacture industries is pipe fitting. PT Flo Bend Indonesia is the only manufacturer of pipe fitting steel and iron in Indonesia. The production process of pipe fitting is carried by the machining process. Quality of product produced by PT Flo Bend is depended on jig and fixture. Some of the problems that often appear are the variation of the material dimension that can disturb the beveling process. The time is needed to be longer to change the jig and fixture that suitable with material that needs to be cut. Therefore, this study was conducted to solve the problems by designing the jig and fixture that are more flexible and can adjust to the varying material dimension. The design focuses on the varying of concentric reducer size. Fishbone diagram was used to analyze the problems so that the approximate design concept can be determined. The result of FEM simulation shows 27,3 MPa for the stress maximum and 8,1 for Factor of safety. Based on FMEA simulation, the design can reduce the time almost 600 minutes. In addition, the design can reduce the cost of the process. Therefore, it can be concluded that the design concept is safe to use.
\end{abstract}

Keywords: Jig \& Fixture, Pipe Fitting, Concentric Reducer, FEM, FMEA.

\begin{abstract}
Abstrak
Perkembangan industri manufaktur di dunia semakin pesat terutama di Indonesia. Salah satu jenis industri manufaktur adalah pipe fitting. PT. Flo Bend Indonesia merupakan satu-satunya produsen manufaktur pipe fitting logam besi dan baja di Indonesia. Proses produksi pipe fitting dilakukan dengan proses machining. Kualitas produk yang dihasilkan PT. Flo Bend dipengaruhi oleh jig dan fixture yang digunakan. Beberapa masalah yang sering timbul adalah dimensi material yang bervariasi sehingga dapat menganggu proses beveling. Waktu yang diperlukan menjadi lebih lama karena harus mengganti jig dan fixture sesuai dengan dimensi material yang akan dipotong. Oleh karena itu, penelitian ini dilakukan untuk menyelesaikan permasalahan tersebut dengan merancang dan memilih jig dan fixture yang lebih fleksibel dan dapat menyesuaikan dengan dimensi material yang bervariasi. Rancangan berfokus pada concentric reducer dengan ukuran bervariasi. Metode diagram fishbone digunakan untuk menganalisis permasalahan sehingga dapat ditentukan konsep rancangan yang sesuai. Berdasarkan hasil simulasi FEM menunjukan bahwa nilai stress maksimum adalah 27,3 Mpa dan nilai Factor of Safety adalah 8,1. Sedangkan untuk FMEA dapat mereduksi waktu hingga 600 menit.Selain itu juga, rancangan baru dapat mengurangi biaya proses. Oleh karena itu, dapat disimpulkan bahwa konsep rancangan yang dibuat aman untuk digunakan.
\end{abstract}

Kata kunci: Jig \& Fixture, Pipe Fitting, Concentric Reducer, FEM, FMEA.

Pendahuluan

Perkembangan industri manufaktur di dunia semakin pesat terutama di Indonesia. Berdasarkan Purchasing Manager's Index (PMI), indeks indonesia adalah 50,4 pada bulan November dan 51,2 pada bulan Desember tahun 2018 sehingga dapat dikatakan bahwa industri manufaktur Indonesia semakin meningkat. Salah satu jenis industri manufaktur adalah pipe fitting. Pt. FloBend Indonesia merupakan satu-satunya produsen manufaktur pipe fitting logam besi dan baja di Indonesia. Perusahaan ini berlokasi di Kota Batam dan berdiri pada tahun 2018 dengan salah satu tujuan dari perusahaan ini adalah untuk mendukung 
revolusi industri Indonesia yaitu industri 4.0. Jenis pipe fitting yang diproduksi oleh perusahaan ini diantaranya adalah elbow, reducer, tee dan cap.

Pipe fitting adalah komponen pipa buatan yang digunakan untuk fungsi spesifik seperti membuat perubahan arah menggunakan elbow, cabang baru dengan tee dan mengurangi diameter pipa menggunakan reducer [1][2][3]. Pipe fitting merupakan salah satu komponen yang diperlukan oleh industri Oil \& Gas. Industri ini mengalami peningkatan kapasitas produksi yang berdampak langsung terhadap industri pendukungnya yaitu industri pipe fitting. Secara umum, produksi pipe fitting oleh PT. Flo Bend dilakukan dengan proses machining. Beveling merupakan salah satu tahap dan fokus utama dalam proses ini. Beveling adalah proses pemotongan pipa untuk membentuk permukaan pipa menjadi $45^{\circ}$ yang berfungsi untuk menyambungkan dua pipa saat proses pengelasan [1]. Beveling sangat dipengaruhi oleh kualitas dari jig dan fixture karena kedua alat ini berfungi untuk membantu pembuatan fitting salah satunya adalah sebagai penahan agar penggandaan dalam proses produksi dapat dilakukan secara presisi dan akurat. Jig dan fixture merupakan dua alat yang berbeda tetapi memiliki fungsi yang saling menunjang satu sama lain [4]. Jig merupakan alat pemotongan dan kontrol sedangkan fixture adalah alat untuk membantu dalam menahan komponen agar tidak ada pergerakan yang mempengaruhi akurasi [5]. Jig lebih ringan dibandingkan dengan fixture dan lebih kompleks. Kedua alat ini merupakan alat yang berguna untuk meningkatkan produk yang dihasilkan per unit waktu karena dapat membantu menghasilkan produk dengan cara duplikasi atau penggandaan lebih akurat. Kekurangan dari alat bantu ini adalah pemilihan jenisnya karena jika memiliki harga tinggi akan meningkatkan biaya produksi [5].

Kualitas produk yang dihasilkan PT. Flo Bend dipengaruhi oleh kedua alat ini. Beberapa masalah yang sering timbul adalah dimensi material yang bervariasi sehingga dapat menganggu proses beveling. Salah satunya adalah waktu yang diperlukan menjadi lebih lama karena harus mengganti jig dan fixture sesuai dengan dimensi material yang akan dipotong [6][7]. Oleh karena itu, penelitian ini dilakukan untuk menyelesaikan permasalahan tersebut dengan merancang dan memilih jig dan fixture yang lebih fleksibel dan dapat menyesuaikan dengan dimensi material yang bervariasi. Perancangan kedua alat ini berfokus pada fitting dengan jenis concentric reducer dengan ukuran 12". 10", 8", dan 6". Dalam penelitian ini digunakan metode diagram fish bone (diagram Ishikawa) untuk menentukan dan menganalisis permasalahan dan efeknya sehingga dapat ditentukan alat seperti apa yang harus dirancang dalam menyelesaikan permasalahan tersebut.

\section{Metode Penelitian}

Penelitian ini dilakukan di PT. Flo Bend Indonesia. Pengumpulan data dilakukan dengan observasi terhadap mesin bevel, jig dan fixture pipe fitting concentric reducer, dan mesin penunjang lainnya dalam proses produksi pipe fitting. Selain itu juga dilakukan wawancara langsung kepada operator mesin bevel di perusahaan untuk mengetahui lebih rinci mengenai kekurangan mesin, operator dan prosedur dalam penggunaan jig dan fixture. Kemudian dibuat daftar kebutuhan dan alternatif desain jig dan fixture untuk mempermudah dalam pembuatan konsep desain. Diagram fishbone digunakan untuk mengidentifikasi sebab akibat dalam 
penggunaan jig dan fixture yang ada di perusahaan [8][9].

Alat dan material yang digunakan dapat penelitian ini adalah solidwork yang merupakan perangkat lunak CAD untuk membantu proses desain suatu benda atau bangunan dengan mudah dalam proses membuat rancangan desain jig \& fixture. Sedangkan untuk pengukuran digunakan alat ukur seperti jangka sorong dan mistar untuk mengukur dimensi dari jig dan fixture.

\section{Hasil dan Pembahasan}

Diagram fishbone yang digunakan untuk mengidentifikasi kekurangan dari desain jig dan fixture di lokasi penelitian dapat dilihat pada Gambar 1.
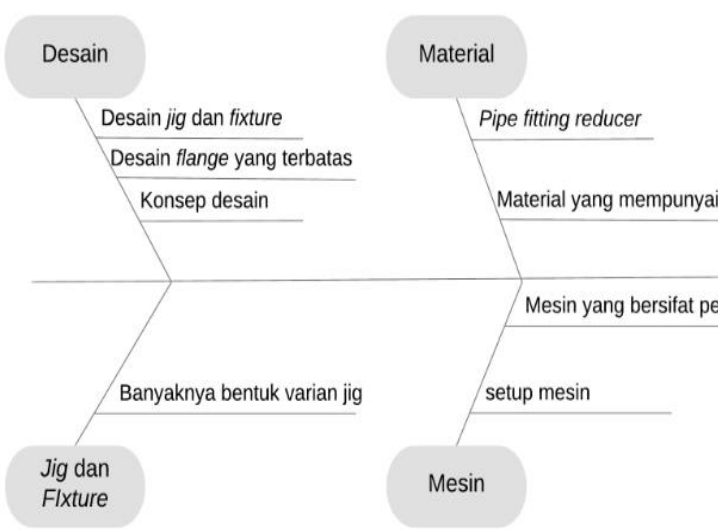

Gambar 1. Diagram Fishbone

Tabel 1. Kekurangan jig dan fixture di PT. Flo Bend Indonesia

\begin{tabular}{|c|c|c|}
\hline No & Tema & Kekurangan \\
\hline 1. & Desain & $\begin{array}{l}\text { Desain flange terbatas. Desain flange hanya bisa diganti satu sisi. } \\
\text { Hal ini dapat mempersulit operator karena harus mengganti jig dan } \\
\text { fixture saat menggunakan material yang memiliki dimensi berbeda }\end{array}$ \\
\hline 2. & Mesin & $\begin{array}{l}\text { Mesin Beveling PE } 16 \text { hanya dapat mengerjakan item material } \\
\text { concentric reducer dengan ukuran 12x10 inci, 8x6 inci dan 10x8 } \\
\text { inci }\end{array}$ \\
\hline 3. & Operator & $\begin{array}{l}\text { Tidak diberi pelatihan dan kurang ketelitian dapat mempersulit } \\
\text { dalam proses pergantian jig dan fixture }\end{array}$ \\
\hline 4. & Material & $\begin{array}{l}\text { Operator harus mengganti jig dan fixture sesuai dengan jenis item } \\
\text { material. }\end{array}$ \\
\hline 5. & Metode & $\begin{array}{l}\text { Pergantian jig dan fixture dilakukan dengan prosedur manual } \\
\text { menggunakan Crane manual dan Forklip }\end{array}$ \\
\hline
\end{tabular}

Berdasarkan Gambar 1 dapat diidentifikasi kekurangan dari jig dan fixture yang terdapat di lokasi penelitian. Hal ini dapat dilihat pada Tabel 1.

\section{a. Perancangan Jig dan Fixture}

Berdasarkan identifikasi kekurangan yang dilakukan maka perancangan jig dan fixture mengacu pada hasil identifikasi tersebut. Perancangan jig dan fixture terdiri dari beberapa tahapan seperti membuat konsep desain base plate

dan konsep desain flange. Perancangan desain jig dan fixture memperhatikan kriteria tertentu seperti mempunyai konstrusi yang sederhana serta mudah dalam proses pengerjaan dan perawatannya. Rancangan untuk desain jig dan fixture dapat dilihat pada Gambar 2.$$
\text { metode }
$$

Prosedur dilakukan manua



Sulitnya pergantian jig dan fixture

Pekerja

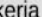

\section{.}


Dudukan base plate merupakan penompang utama dari fixture. Base plate dirancang menjadi 2 bagian yaitu atas dan bawah dengan bagian sisi kiri dan kanan

memiliki slop yang berfungsi sebagai tempat pemasangan flange.

Kedua sisi samping ini memiliki 8 lubang dan mempunyai ulir sebagai tempat masuknya baut sebagai pengunci flange Rancangan ini mempunyai dua sisi slop yang dapat dibongkar pasang, agar lebih mudah pada saat proses pergantian flange dan dapat melengkapi kekurangan desain sebelumnya yaitu dengan pembuatan jalur aliran keluar coolant yang berfungsi untuk menghindari air coolant dapat tertampung pada bagian jig dan fixture.

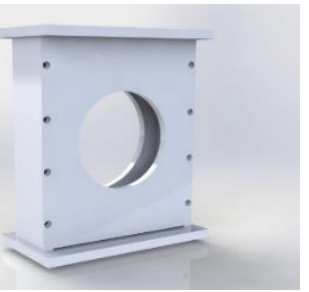

Gambar 2. Desain Jig dan Fixture

Spesifikasi base plate dapat dilihat pada Gambar 3.

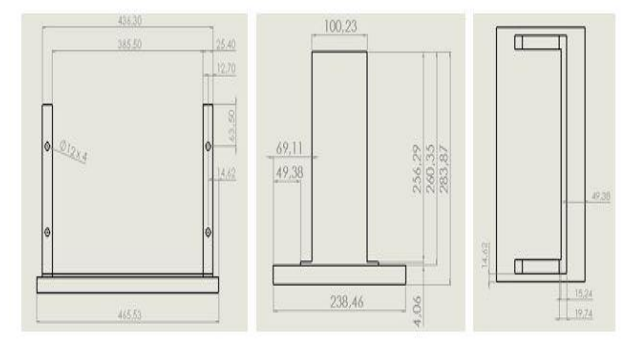

(a)

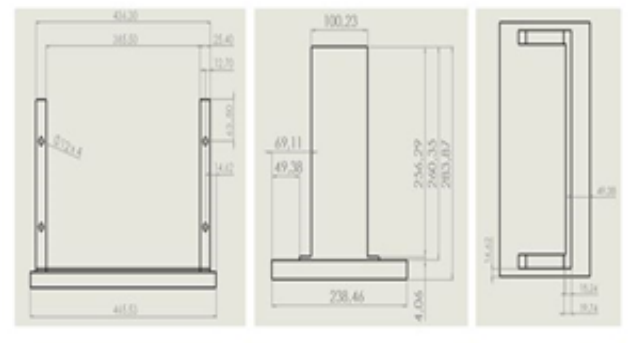

(b)

Gambar 2. Spesifikasi Base Plate, a) Down, b) Up

Pembuatan Konsep Desain Flange
Jig dan fixture dirancang memiliki 8 buah flange dengan ukuran 6", 8", 10"dan 12". Ukuran ini mengacu pada outer diamater (OD) pipe fitting dengan masing-masing ukuran memilki 2 pasang flange. Rancangan berupa persegi panjang dengan lubang berbentuk setengah lingkaran yang mengikuti ukuran pipe fitting di bagian tengah (Gambar 4).
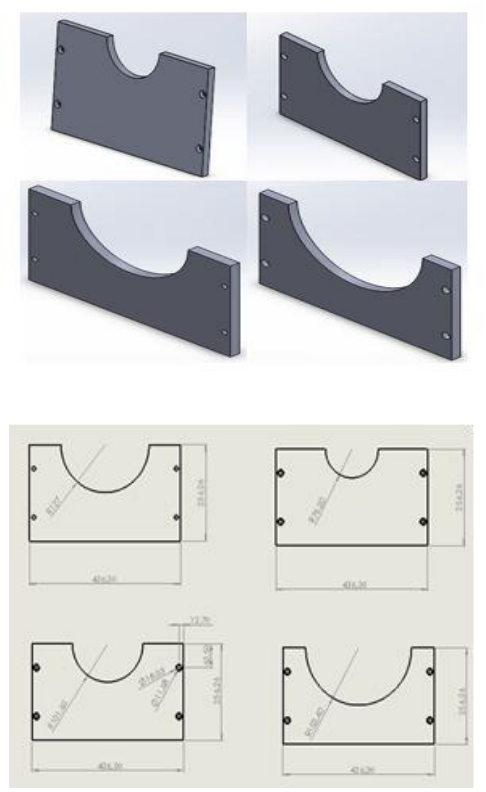

Gambar 4. Rancangan dan Spesifikasi Flange

Simulasi dilakukan dengan memberikan jumlah mesh sebesar 10.000 karena jumlah dan bentuk mesh sangat berpengaruh pada hasil simulasi. Hasil lebih akurat dalam memberikan informasi mengenai jig dan fixture yang mengalami penekanan oleh gaya tekan jika mesh yang diberikan semakin banyak dan bentuknya semakin kecil.

\section{Analisa Struktur FEM}

\section{Stress}

Berdasarkan Gambar 5 dapat dilihat bahwa warna reaksi tidak terlalu signifikan karena masih dalam kategori hijau dan biru. Beban tekan diberikan pada jig dan fixture sebesar 0,4 Mpa yang berasal dari hidrolik mesin bevel. Nilai tegangan maksimal dari hasil pengujian adalah 27,3 Mpa. Nilai ini masih di 
bawah nilai yield strength dari material yaitu sebesar $220 \mathrm{Mpa}$. Oleh karena itu, pembebanan pada alat masih dalam kategori pembebanan elastis.

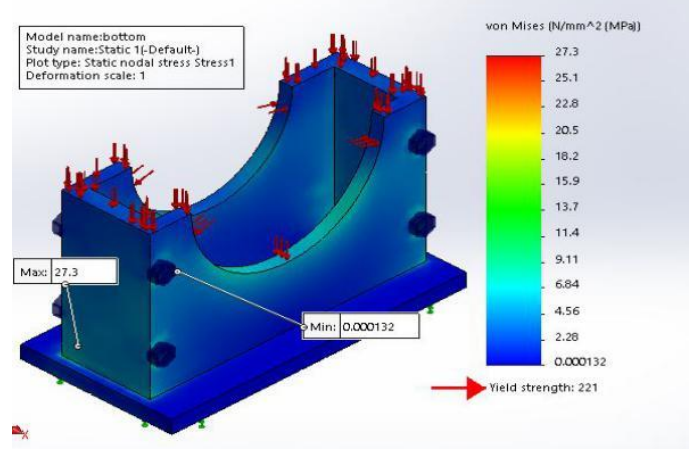

Gambar 5. Simulasi Stress Jig dan Fixture

\section{Factory of Safety}

Hasil pengujian factor of safety adalah 8,1 dan dapat dikatakan bahwa alat yang dirancang dapat menahan beban maksimal 8 kali beban yang diberikan. Hal ini dapat dilihat pada Gambar 6.

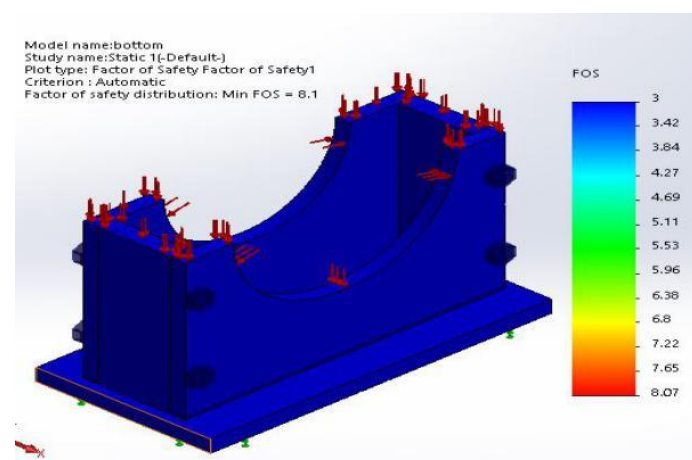

Gambar 6. Simulasi Factor of Safety dari Jig dan Fixture

\section{Analisa Perbandingan Waktu Set-up (FMEA)}

Rancangan jig dan fixture ini dapat menghasilkan waktu setup yang lebih kecil dan hal ini akan memberikan keuntungan dalam waktu pengerjaan suatu komponen yaitu waktu berkurang 600 menit. Hal ini dapat dilihat pada tabel 2.

Tabel 2. Perbandingan Waktu Setup dari Jig dan Fixture Lama dan Baru

\begin{tabular}{lccc}
\hline Tipe Alat & $\begin{array}{c}\text { Waktu Setup } \\
\text { (menit) }\end{array}$ & Jumlah & $\begin{array}{c}\text { Waktu Total } \\
\text { (Menit) }\end{array}$ \\
\hline Lama & 300 & 3 set & 900 \\
Baru & 300 & 1 set & 300 \\
& & Waktu yang Berkurang & $\mathbf{6 0 0}$ \\
\hline
\end{tabular}

\section{Analisa Kelayakan Ekonomis}

Analisis ini dilakukan untuk mengetahui kelayakan ekonomis dari alat yang dirancang hal ini dapat dilihat pada Tabel 3.

Tabel 3. Perbandingan Biaya Pembuatan Jig dan Fixture (Lama dan Baru)

\begin{tabular}{|c|c|c|c|c|c|c|}
\hline \multirow[t]{2}{*}{ Tipe alat } & \multicolumn{3}{|c|}{ Dimensi (mm) } & \multirow{2}{*}{$\begin{array}{c}\text { Jumlah } \\
\text { (set) }\end{array}$} & \multirow[t]{2}{*}{ Harga Unit } & \multirow[t]{2}{*}{ Total Harga } \\
\hline & $\mathrm{P}$ & $\mathrm{L}$ & $\mathrm{T}$ & & & \\
\hline Lama & 466 & 238 & 19,7 & 3 & Rp. 11.800 .000 & Rp. 35.400 .000 \\
\hline Baru & 466 & 238 & 19,7 & 1 & $\begin{array}{c}\text { Rp. } 5.592 .000 \\
\text { Harga yang } \\
\text { berkurang }\end{array}$ & $\begin{array}{c}\text { Rp. } 5.592 .000 \\
\text { Rp. } \mathbf{2 9 . 8 0 8 . 0 0 0}\end{array}$ \\
\hline
\end{tabular}

\section{Kesimpulan}

Berdasarkan konsep rancangan jig dan fixture yang telah dibuat dapat disimpulan bahwa rancangan baru dapat menghemat biaya sebesar Rp. 29.808.000 dan waktu setup berkurang 600 menit sehingga proses pengerjaan pada mesin bevel lebih efektif dan efisien. Selain itu juga, hasil simulasi menunjukan bahwa nilai stress maksimum adalah 27,3 Mpa dan nilai Factor of Safety adalah 8,1. Oleh karena itu, dapat disimpulkan bahwa konsep rancangan yang dibuat aman untuk digunakan. 


\section{Ucapan Terima Kasih}

Penelitian ini terselenggara didalam skema Program Magang Setahun di Industri, PT. Flo-Bend Indonesia.

\section{Daftar Pustaka}

[1] J. A. Williams, "Fundamentals of metal cutting and machine tools," Mater. Des., 1988, doi: 10.1016/0261-3069(88)90021-0.

[2] R. A. Parisher and R. A. Rhea, "Overview of Pipe Drafting and Design," in Pipe Drafting and Design, 2012.

[3] R. M. Mahaffey and S. J. Van Vuuren, "Review of pump suction reducer selection: Eccentric or concentric reducers," Journal of the South African Institution of Civil Engineering. 2014.

[4] J. Vijaykumar Kumbhar and H. C. Pandit, "A Review Article on Jigs and Fixture," 2015.

[5] E. G.Hoffman, Jig and Fixture Design, 5th ed. New York: DELMAR CENGAGE Learning, 2004.

[6] A. Santosa, "Perancangan Jig Dan Fixture Sistem Pneumatik Untuk
Proses Pemasangan Bearing Dan Absorber Pada Velg Rear Wheel," Barom. Ilmu dan Apl. Tek., vol. 2, no. 1, pp. 1-5, 2017.

[7] H. Prassetiyo, R. Rispianda, and H. Adanda, "RANCANGAN JIG DAN FIXTURE PEMBUATAN PRODUK COVER ON-OFF," Teknoin, 2016, doi: 10.20885/teknoin.vol22.iss5.art4.

[8] M. Coccia, "The Fishbone Diagram to Identify, Systematize and Analyze the Sources of General Purpose Technologies," J. Soc. Adm. Sci., 2017.

[9] N. Fauziah, "Aplikasi Fishbone Analysis dalam Meningkatkan Kualitas Produksi Teh pada PT Rumpun Sari Kemuning, Kabupaten Karanganyar,” 2009. 